\title{
A pastoral judiciária e o processo de nulidade matrimonial
}

\author{
The judicial pastoral and the matrimonial nullity process
}

\section{Valdinei de Jesus Ribeiro ${ }^{1}$}

Resumo: A aplicação e bom êxito da reforma do processo de nulidade matrimonial realizada pelo Papa Francisco depende, em boa medida, da implantação de uma Pastoral Judiciária, razão pela qual é preciso explorar um pouco mais este tema. Para bem compreendê-lo, urge situá-lo no contexto do Sínodo da Família, do qual redundou a Exortação Apostólica Pós-Sinodal Amoris Laetitia. Nela, se faz alusão a um necessário dis-
Abstract: The implementation and success of the reform of the matrimonial nullity process conducted by Pope Francis depends, to a great extent, on the implementation of a Judicial Pastoral, which is why we need to explore this issue a little more. In order to understand it, it is necessary to situate it in the context of the Synod on the Family, which resulted in the Post-Synodal Apostolic Exhortation Amoris Laetitia. In

1 Graduado em Filosofia pelo Centro Universitário Claretiano de Batatais e em Teologia pela Pontifícia Universidade Salesiana de Roma. Especialista em Counseling (Aconselhamento) pelas Faculdades Bagozzi de Curitiba-PR. Mestre e Doutor em Utroque Iure (Direito Canônico e Civil) pela Pontifícia Universidade Lateranense (Cidade do Vaticano) - título convalidado no Brasil pela PUCRJ. Atualmente é professor do Instituto Superior de Direito Canônico Santa Catarina em Florianópolis - SC e colabora com o Pontifício Instituto Superior de Direito Canônico do Rio de Janeiro - extensão Londrina-PR. É professor da Faculdade Claretiana de Teologia (Studium Theologicum) em Curitiba-PR e Vigário Judicial Adjunto do Tribunal Eclesiástico Interdiocesano e de Apelação de Curitiba - PR.

Graduated in Philosophy from the Claretiano - Centro Universitário of Batatais and in Theology from the Università Pontificia Salesiana of Roma. Expert on Counseling from the Faculdades Bagozzi of Curitiba-PR. Master and Doctor in Utroque Iure (Canon and Civil Law) from the Pontificia Università Lateranense (Vatican City) - title validated in Brazil by PUC-RJ. He is currently a professor at the Instituto Superior de Direito Canônico Santa Catarina in Florianópolis SC and collaborates with the Pontifício Instituto Superior de Direito Canônico of Rio de Janeiro - extension Londrina-PR. He is a professor at the Faculdade Claretiana de Teologia (Studium Theologicum) in Curitiba-PR and Judicial Vicar of the Inter-diocesan Ecclesiastical and Appealing Court of Curitiba - PR. 
cernimento, conforme a verdade, que não permite uma ruptura ou contraposição entre o processo judicial e a Pastoral Judiciária, razão pela qual esta necessita ser pensada e estruturada em função daquele. Na busca de se criar condições para que este discernimento ocorra, é importante assumir uma atitude de fundo: a de uma Igreja em saída. Por isso, na estruturação desta pastoral, a preocupação será a de levar o serviço até as pessoas e não o inverso. Trata-se de um grande desafio que poderá produzir ótimos frutos caso seja assumido por todos, particularmente por aqueles aos quais foi confiado o cuidado pastoral das comunidades.

Palavras-chaves: Sínodo; discernimento; Pastoral Judiciária; processo judicial. it, reference is made to a necessary discernment, according to the truth, which does not allow a rupture or opposition between the judicial trial and the Judicial Pastoral, which is why the judicial pastoral needs to be thought and structured according to the judicial process. In order to create conditions for this discernment to occur, it is important to adopt a fundamental attitude: that of an outgoing Church. In the structuring process of this pastoral, the concern will consist in taking the service to the people and not the other way around. This is a great challenge that could produce great results if accepted by everybody, particularly by those entrusted with the pastoral care of the communities.

Keywords: Synod; discernment; Judicial Pastoral; judicial process.

\section{Introdução}

A aplicação e bom êxito da reforma do processo de nulidade matrimonial realizada pelo Papa Francisco com os recentes Motu proprio Mitis Iudex Dominus Iesus (MIDI) e Mitis et Misericors Iesus $(M M I)^{2}$, depende, em boa medida, de sua inserção no contexto de uma renovada Pastoral Judiciária.

2 FRANCISCUS PP., Litterae Apostolicae Motu proprio datae Mitis Iudex Dominus quibus canones Codicis Iuris Canonici $[=C I C]$ de Causis ad Matrimonii nullitatem declarandam reformantur, in AAS, 107 (2015), pp. 958-970; FRANCISCUS, Litterae Apostolicae Motu proprio datae Mitis et Misericors Iesus quibus canones Codex Canonum Ecclesiarum Orientalium $[=C C E O]$ de Causis ad Matrimonii nullitatem declarandam reformantur, in AAS, 107 (2015), pp. 946-957. Para o texto em português ver a seguinte obra: Cartas apostólicas do Papa Francisco em forma de Motu proprio Mitis Iudex Dominus Iesus e Mitis et Misericors Iesus sobre a reforma do processo canônico para as causas de declaração de nulidade do matrimônio no Código de Direito Canônico e no Código dos Cânones das Igrejas Orientais. CNBB, Brasília, 2015. — Todas as demais refe- 
As mudanças efetuadas pelo Romano Pontífice visam encurtar o distanciamento entre as estruturas judiciárias da Igreja e os fiéis e multiplicar o serviço da justiça para que, dessa forma, se torne mais acessível e ágil o desenvolvimento do processo judicial, pois, como bem observou o Papa, "a lentidão dos processos irrita e cansa as pessoas"3. Neste sentido, o tema da Pastoral Judiciária permeia toda a legislação alterada pela reforma e, portanto, não se encontra isolado nas referências explícitas a ele feitas no Proêmio e nas Regras Processuais para o tratamento das causas de Nulidade Matrimonial (RPNM).

A agilidade e celeridade do processo, pretendidas pela mudança na lei, unidas sempre a um sério discernimento, tendo em vista uma decisão conforme a verdade, deixarão de ser um simples desejo, caso a Pastoral Judiciária se torne realidade. Em contrapartida, sem a implantação e efetivo funcionamento dessa pastoral é improvável que as mudanças na legislação logrem o êxito almejado.

A Pastoral Judiciária insere-se no âmbito da pastoral ordinária e, especificamente, no da Pastoral Familiar ${ }^{4}$. Isso requer uma mudança de mentalidade, que supere a equivocada contraposição entre direito e pastoral e esteja aberta à necessária "conversão pastoral", à qual faz alusão o Papa Francisco nos números 25-33 da Exortação Apostólica Evangelii Gaudium $(E G)^{5}$.

Este artigo, de natureza jurídico-pastoral, pretende oferecer uma modesta contribuição para o desenvolvimento desse tema, ainda pouco explorado ${ }^{6}$ desde a promulgação da reforma do processo de nulida-

rências advindas do MIDI estarão, de agora em diante, assim enunciadas, dispensando a nota de rodapé.

3 FRANCISCUS PP., Adhortatio Apostolica Post-Synodalis Amoris Laetitia [=AL], in $A A S, 108$ (2016), no 244, p. 409.

4 FRANCISCUS PP., Adhortatio Apostolica Post-Synodalis Amoris Laetitia, $\mathrm{n}^{\mathrm{o}}$ 244, p. 410. Nas RPNM o Pontífice usa a expressão "pastoral matrimonial" (Cf. Art. 2). Estas duas expressões utilizadas em dois documentos pontifícios distintos, mas do mesmo autor, podem ser tomadas como equivalentes, pois o Papa na $A L$, ao utilizar a expressão "Pastoral Familiar", cita explicitamente o Art. 2 do MIDI.

5 FRANCISCUS PP., Adhortatio Apostolica Evangelii Gaudium, in AAS, 105 (2013), nn. 25-33, pp. 1030-1034.

6 A propósito da Pastoral Judiciária, consultar: AAVV, La riforma dei processi matrimoniali di Papa Francesco: una guida per tutti, Ancora, Milano, 2016, pp. 
de matrimonial. Por conseguinte, o aparato crítico do presente estudo não será tão amplo e variado. Tentar-se-á, após uma breve contextualização, oferecer algumas pistas que, talvez, possam auxiliar na compreensão do que seria essa pastoral e de como funcionaria, particularmente em relação à realidade brasileira. Procurar-se-á destacar em que medida essa pastoral poderia favorecer a atividade judiciária da Igreja, tornando-a mais ágil e célere, ao menos em relação às causas matrimoniais.

Como substancialmente o conteúdo do $M I D I$ é idêntico ao do $M M I$, as ideias desenvolvidas no texto tomarão por referência apenas a legislação latina, podendo ser aplicadas, mutatis mutandis, ao contexto oriental.

\section{O Sínodo da Família e a Exortação Apostólica Pós-Sinodal Amoris Laetitia}

Como ponto de partida para o estudo da reforma e, particularmente, da Pastoral Judiciária, é forçoso situá-la no contexto maior do pontificado do Papa Francisco, como, também, no contexto imediato da III Assembleia Geral Extraordinária do Sínodo dos Bispos (05 a 19.10.2014), e da XIV Assembleia Geral Ordinária do Sínodo dos Bispos (04 a 25.10.2015) ${ }^{7}$. O quanto produzido nessas duas Assembleias Sinodais, voltadas para a família, resultou na Exortação Apostólica Pós-Sinodal Amoris Laetitia $(A L)$. Este evento sinodal é um importante critério hermenêutico para a análise e compreensão das mudanças realizadas na legislação ${ }^{8}$.

9-27; M. J. ARROBA CONDE - C. IZZI, Pastorale giudiziaria e prassi processuale nelle cause di nullità del matrimonio, San Paolo, Milano, 2017; J. A. GONÇALVES DE ALMEIDA, (organizador), Vade-mécum do Motu Proprio Mitis Iudex Dominus Iesus, CNBB, Brasília, 2017; V. J. RIBEIRO, A reforma do processo de nulidade matrimonial: um exame do Motu proprio Mitis Iudex Dominus Iesus, CNBB, Brasília, 2016.

7 A respeito da reforma e sua gênese no Sínodo dos Bispos, ver: V. J. RIBEIRO D. GERALDO, A reforma no processo de nulidade matrimonial e sua gênese no Sínodo dos Bispos, in Revista Eclesiástica Brasileira (REB), v. 302, 2016, p. 356-374.

8 Para Arroba Conde, o Sínodo da Família (as duas Assembleias) é o contexto próprio da mudança na normativa e, também, obrigatório, no sentido hermenêu- 
A Relatio Synodi da III Assembleia Geral Extraordinária do Sínodo dos Bispos, que se ocupou dos desafios pastorais sobre a família no contexto da evangelização, dedicou dois números (48-49) aos processos de nulidade matrimonial ${ }^{9}$. Nela, foram recolhidas algumas propostas da fase de preparação do Sínodo contidas no Instrumentum Laboris $^{10}$. Algumas foram aceitas e incorporadas ao MIDI; outras foram rejeitadas, como, por exemplo, a de se adotar um procedimento de natureza administrativa no discernimento acerca da nulidade do matrimônio. No $\mathrm{n}^{0} 49$ situa-se a primeira menção à Pastoral Judiciária, chamando-se a atenção para a necessidade de se incentivar a preparação de pessoas que possam se dedicar integralmente a este serviço.

A Relatio Synodi da XIV Assembleia Geral Ordinária do Sínodo dos Bispos, que se ocupou da vocação e missão da família na Igreja e no mundo contemporâneo, dedicou apenas o $\mathrm{n}^{\mathrm{o}} 82$ à Pastoral Judiciária. Uma vez que os recentes Motu proprio MIDI e MMI já haviam si-

tico estabelecido pelo cân. 17. Para o autor, em um sentido análogo, as duas Assembleias sidonais estão para a reforma do processo de nulidade matrimonical, como o Concílio Vaticano II está para o Código de Direito Canônico. Cf. M. J. ARROBA CONDE - C. IZZI, Pastorale giudiziaria e prassi processuale nelle cause di nullità del matrimonio, p.11.

9 SÍNODO DOS BISPOS. III Assembleia geral extraordinária do Sínodo dos Bispos: Os desafios pastorais sobre a família no contexto da evangelização. (online) <http://www.vatican.va/roman_curia/synod/documents/rc_synod_doc_2014 1018 relatio-synodi-familia_po.html $>$ Acessado aos 30/06/2017.

10 O Instrumentum Laboris da Assembleia geral extraordinária, publicado aos 24.06.2014, foi construído em três partes. No Capítulo III da II Parte, especificamente nos números 97-102, encontram-se as propostas que se ocupavam dos processos de nulidade matrimonial. Para acessar o texto (on-line): $<$ http://www.vatican.va/roman_curia/synod/documents/rc_synod_doc_20140626 _instrumentum-laboris-familia_po.html $>$. Acessado aos 30/05/2017. Já o Instrumentum Laboris da Assembleia geral ordinária, publicado aos 23.06. 2015, foi composto pelo texto definitivo da Relatio Synodi da Assembleia anterior, integrado pela síntese das respostas, observações e contribuições aportadas ao texto. $\mathrm{O}$ documento possui três partes que mostram a continuidade entre as duas Assembleias. Na terceira parte, nos números 114-117, foram agrupadas as propostas que se ocupavam dos processos de nulidade matrimonial e que, em boa parte, refletem o quanto contido na Relatio Synodi. Para acessar o texto (on-line): $<$ http://www.vatican.va/roman_curia/synod/documents/rc_synod_doc_20150623 instrumentum-xiv-assembly_po.html >. Acessado aos 30/06/2017. 
do promulgados, a eles se fez menção neste documento ao se referir a ela:

Para muitos fiéis que viveram uma experiência matrimonial infeliz, a averiguação da nulidade do seu matrimónio representa um caminho a percorrer. Os recentes Motu proprio Mitis Iudex Dominus Iesus e Mitis et Misericors Iesus levaram a uma simplificação dos procedimentos para a eventual declaração de nulidade matrimonial. Com estes textos, o Santo Padre quis também «evidenciar que o próprio Bispo na sua Igreja, da qual está constituído pastor e chefe, é por isso mesmo juiz no meio dos fiéis a ele confiados» (MI, preâmbulo, III). Por conseguinte, a prática destes documentos constitui uma grande responsabilidade para os Ordinários diocesanos, chamados a julgar eles mesmos algumas causas e, de qualquer modo, a assegurar um acesso mais fácil dos fiéis à justiça. Isto comporta a preparação de pessoal suficiente, composto por clérigos e leigos, que se consagre de forma prioritária a este serviço eclesial. Portanto, será necessário pôr à disposição das pessoas separadas ou dos casais em crise, um serviço de informação, de aconselhamento e de mediação, ligado à Pastoral Familiar, que também poderá receber as pessoas em vista da investigação preliminar ao processo matrimonial (cf. MI, arts. 2-3) ${ }^{11}$.

É preciso reconhecer que o Magistério Pontifício, desde a Exortação Apostólica Familiaris Consortio $(F C)$, do Papa São João Paulo II $^{12}$, até a $A L$, do Papa Francisco ${ }^{13}$, há muito tempo vem insistindo na importância da Igreja se fazer próxima dos cônjuges que interromperam a vida conjugal, chegando à separação legal e, não raramente, até o divórcio.

O Papa São João Paulo II dedicou à Pastoral Familiar a quarta parte da $F C$, ocupando-se de suas etapas, estruturas, responsáveis e de

11 SÍNODO DOS BISPOS. XIV Assembleia geral ordinária: A vocação e a missão da família na Igreja e no mundo contemporâneo (on-line) <http://www. vatican.va/roman_curia/synod/documents/rc_synod_doc_20151026_relazionefinale-xiv-assemblea_po.html $>$. Acessado aos 30/05/2017. IOANNES PAULUS PP. II, Adhortatio Apostolica Familiaris Consortio, in $A A S, 74$ (1982), nn. 83-84, pp. 184-186.

13 FRANCISCUS PP., Adhortatio Apostolica Post-Synodalis Amoris Laetitia, nn. 241-246, pp. 408-411. 
situações diversas ${ }^{14}$. Este documento pontifício serviu como base para que as diversas conferências episcopais elaborassem o seu diretório da Pastoral Familiar e se ocupassem daqueles que por diversas razões não puderam levar adiante o próprio matrimônio. No Brasil, a CNBB publicou o Diretório da Pastoral Familiar que foi discutido e aprovado pela 42a Assembleia Geral realizada entre os dias 21-30 de abril de 2004. Neste documento, o Capítulo 7 é dedicado a algumas "situações especiais", dentre as quais se menciona aqueles que casaram na Igreja, realizaram o divórcio civil e hoje se encontram em uma nova união civil. Os nn $n^{\circ} 396$ e 397 contêm as seguintes orientações:

Procure-se, também, facilitar-lhes o acesso aos tribunais eclesiásticos, para estudar a possível existência de causas que determinem a declaração de nulidade do matrimônio anterior, pois, em caso positivo, ficariam habilitados para contrair o matrimônio sacramental.

Organizem-se encontros ou retiros específicos, a fim de que, por meio deles, esses casais possam descobrir o modo de solucionar a irregularidade em que se encontram ou os canais de participação acima mencionados, e se sintam parte integrante da comunidade eclesial ${ }^{15}$.

O documento da CNBB propõe, então, que se facilite o acesso aos tribunais eclesiásticos e se organizem encontros e retiros específicos com aqueles que fizeram o divórcio civil e se encontram em uma nova união civil. Agora, após o $M I D I$, é certo que a realidade requer uma ação bem mais articulada do quanto proposto no texto apenas citado, razão pela qual alguns passos precisarão ser dados nessa direção. Urge oferecer a essas pessoas uma ajuda que, de fato, favoreça o seu caminho espiritual, não obstante as dificuldades e os sofrimentos decorrentes da situação na qual se encontram ${ }^{16}$.

14 Cf. IOANNES PAULUS PP. II, Adhortatio Apostolica Familiaris Consortio, nn. 65-85, pp. 158-187.

15 CONFERÊNCIA NACIONAL DOS BISPOS DO BRASI, Diretório da Pastoral Familiar, Documentos da CNBB 79, Paulinas, São Paulo, 2005, nn. 396-397.

16 Como bem observou o Papa Francisco no Proêmio do MIDI, há um enorme número de fiéis que, embora desejando prover a própria consciência, muitas vezes se afastam das estruturas jurídicas da Igreja por causa da distância física ou mo- 
No Capítulo VI da $A L$, dedicado a algumas perspectivas pastorais, o Papa Francisco fez um elenco dos principais desafios pastorais ligados ao tema da família. No tópico intitulado "Acompanhar depois das rupturas e dos divórcios" (cf. $\mathrm{nn}^{\circ}$ 241-246), reportando-se ao Sínodo da Família, ele alerta para a necessidade de um "indispensável discernimento particular" para acompanhar pastoralmente os separados, os divorciados, os abandonados ${ }^{17}$. Sendo assim, é necessário e possível incluir neste discernimento um questionamento acerca da validade do próprio matrimônio, sem prejuízo do quanto afirmado pelo cân. 1060 do CIC atual ${ }^{18}$. Disso decorre a exigência de um serviço voltado especificamente para este fim.

Há quem, na prática, sequer teve a oportunidade de se questionar sobre a validade do próprio matrimônio que não prosperou por desconhecer essa possibilidade. Há, ainda, os que buscam a nulidade do matrimônio sem, todavia, terem passado por um sério processo de discernimento a respeito da viabilidade daquilo que buscam, dos instrumentos para obtê-la e das implicações de uma escolha do gênero. Tais pessoas, em não raras oportunidades, recorrem ao judiciário da Igreja, ignorando as peculiaridades do seu ordenamento jurídico e, particularmente, desconhecendo as diferenças entre processo civil e processo canônico, embora não faltem elementos comuns, sobretudo, em relação à concepção existente a respeito da natureza, estrutura e dinâmica de um processo judicial. A falta de informação, de discernimento e de uma adequada compreensão do que vem a ser a nulidade do matrimônio e de como obtê-la, contribuem para afastar as pessoas das estruturas judiciárias da Igreja ou, então, dificultam enormemente a celeridade processual, uma vez que as partes acabam por não assumir a postura que delas se espera no processo canônico.

ral; a caridade e a misericórdia exigem que a própria Igreja como mãe se aproxime dos filhos que se consideram segregados.

17 FRANCISCUS PP., Adhortatio Apostolica Post-Synodalis Amoris Laetitia, $\mathrm{n}^{\circ}$ 242, p. 409.

18 JOÃO PAULO II, Codex Iuris Canonici, Promulgado aos 25/01/1983. Tradução oficial: Conferência Nacional dos Bispos do Brasil, Loyola, São Paulo, 2017. - Todas as demais referências advindas do Codex Iuris Canonici (CIC) estarão, de agora em diante, assim enunciadas, dispensando-se a nota de rodapé. 
Para mudar o quadro apenas descrito e favorecer o indispensável discernimento ao qual aludiu o Papa Francisco no no 242 da $A L$, a Pastoral Judiciária realmente seria uma iniciativa de grande valia. Tratarse-ia de um específico serviço de acolhida, orientação, consulta e assessoria voltado diretamente para um discernimento pastoral com o intuito de avaliar a presença, ou não, dos pressupostos necessários para se iniciar uma causa de nulidade matrimonial, como, também, prepará-la. Desta forma, haveria um elo, ou conexão, entre o discernimento judicial e o discernimento pastoral a ele anterior, com a possibilidade de se aportar o resultado deste último às diversas fases do processo de nulidade matrimonial, tornando-o, assim, mais ágil e célere. Todavia, é imperativo não confundir os dois processos, pois se tratam de dois momentos distintos (fase pré-judicial e judicial), com estruturas e dinâmicas próprias, mas conexos, e, portanto, interligados.

Embora situada na fase anterior ao processo, a Pastoral Judiciária poderia, inclusive, se estender ao "pós-processo", uma vez que nem sempre a resposta obtida no processo judicial (sentença) será aquela pretendida ou desejada. Neste caso, urge favorecer, ao máximo, a inserção na vida da comunidade eclesial dos que obtiverem uma sentença negativa para que dela possam participar da melhor forma possível, não obstante os limites que precisarão ser assumidos como consequência do discernimento realizado e da decisão tomada.

\section{O discernimento judicial e a Pastoral Judiciária}

No Proêmio do MIDI, para evitar equívocos ou distorções, o Papa Francisco teve o cuidado de esclarecer que a reforma por ele proposta não tem por objetivo favorecer a nulidade do matrimônio, mas, sim, a celeridade do processo. Mais adiante, pouco antes de expor os critérios fundamentais que guiaram a reforma, o Romano Pontífice afirmou que optou por manter a exigência de um processo de natureza judicial devido à necessidade de se tutelar ao máximo a verdade do sagrado vínculo. Além disso, em se tratando de discutir algo que diz respeito ao próprio estado de vida das pessoas (trata-se de uma vocação), é imperioso reconhecer que seria uma enorme perda privar os fiéis da possibilidade de esclarecer judicialmente a própria situação ma- 
trimonial, sem as garantias que este tipo de processo lhes proporcio$\mathrm{na}^{19}$.

Uma vez mantida a vida judicial, com o intuito de garantir ao fiel um discernimento que lhe permita clarificar a sua real situação diante de si mesmo, da Igreja e de Deus, é necessário, então, oferecerlhe as melhores condições para que isso, de fato, ocorra. Sendo assim, não foi sem razão que o legislador, no livro VII do CIC atual, na parte dedicada aos juízos em geral (cânn.1400-1500), fixou determinadas exigências para a criação de tribunais eclesiásticos e estabeleceu uma série de requisitos para se ocupar os diversos ofícios na estrutura judiciária da Igreja. O Papa Francisco, ciente de tais exigências, optou por mantê-las praticamente intactas e, no $M I D I$, reforçou a importância da formação dos operadores dos tribunais, pois titulação e qualificação são dois requisitos exigidos para se atuar no judiciário da Igreja. Portanto, não se pode afirmar que com a reforma do processo de nulidade matrimonial a criação de tribunais eclesiásticos ficou favorecida devido ao abrandamento das exigências legais para a sua constituição, pois isso não ocorreu ${ }^{20}$. O fato do MIDI permitir que dois leigos integrem o colégio judicante não equivale a uma diminuição nas exigências para se ocupar o ofício de juiz eclesiástico, mas sim favorece, e muito, uma maior presença de leigos no judiciário da Igreja, desde que devidamente formados. Não se deve ignorar que o Art. $8, \S 1$ do texto utiliza

19 Ao optar pelo processo judicial, no qual se exige paridade entre as partes, imparcialidade do juiz, a necessária certeza moral sobre a quaestio facti e uma absoluta fidelidade a quaestio iuris, o Papa Francisco entende que neste tipo de processo se oferece muito mais garantias para se chegar à verdade a respeito da existência ou não do vínculo matrimonial do que no processo de natureza administrativa. De fato, seria muito arriscado deixar que uma decisão de tamanha importância ficasse à mercê de critérios meramente discricionais dos quais se utiliza o poder executivo. Para um estudo das diferenças entre estes dois processos, consultar: M. J. ARROBA CONDE - C. IZZI, Pastorale giudiziaria e prassi processuale nelle cause di nullità del matrimonio, pp. 49-56.

20 A constituição de um tribunal eclesiástico exige, ao menos, três juízes, um defensor do vínculo e um notário. Além disso, as partes deveriam ter a possibilidade de contar com a assistência técnica de um advogado (cân. 1481, §1), embora tenham a possibilidade de agir por si mesmas em algumas causas. Em relação a isso, a legislação não foi modificada e, portanto, continua em vigor. A entrega de uma causa a um juiz monocrático é sempre exceção e nunca a regra. Basta observar o quanto contido no $M I D I$ em relação a esse ponto. 
a expressão "cursos de formação permanente", expressão esta que obviamente pressupõe uma formação inicial, da qual faz parte um título de estudo (mestrado ou doutorado em direito canônico) e a devida qualificação jurídica ${ }^{21}$. De fato, como falar em formação permanente sem que, primeiro, a pessoa tenha a formação inicial requerida para ocupar determinadas funções no judiciário da Igreja? Seria um contrassenso optar pela via judicial e, ao mesmo tempo, retirar as garantias típicas de um processo do gênero justamente pela falta da devida formação e qualificação dos que nele atuariam.

O Papa São João Paulo II, em um discurso à Rota Romana, já tinha se posicionado a respeito da formação dos que atuam no judiciário da Igreja, destacando a importância da busca da verdade e de decisões conforme a reta doutrina:

Nei discorsi annuali alla Rota Romana ho più volte ricordato l'essenziale rapporto che il processo ha con la ricerca della verità oggettiva. Di ciò devono farsi carico innanzitutto i Vescovi, che sono i giudici per diritto divino delle loro comunità. È in loro nome che i tribunali amministrano la giustizia. Essi sono pertanto chiamati ad impegnarsi in prima persona per curare l'idoneità dei membri dei tribunali, diocesani o interdiocesani, di cui essi sono i Moderatori, e per accertare la conformità delle sentenze con la retta dottrina. I sacri Pastori non possono pensare che l'operato dei loro tribunali sia una questione meramente "tecnica" della quale possono disinteressarsi, affidandola interamente ai loro giudici vicari (cfr. CIC, cann. 391, $1419,1423, \S 1)^{22}$.

21 Quanto à titulação, é suficiente se ater aos ditames do cân. 1421, § 3. No que se refere à qualificação, a instrução Dignitas Connubii assim se manifeseta no final do seu Proêmio: "Portanto, incumbe aos Bispos, com grave obrigação de sua consciência, fazer com que sejam formados com solicitude administradores idôneos da justiça para os seus tribunais, e que estes sejam preparados com um adequado tirocínio no foro judicial, para instruir segundo o direito e decidir retamente as causas matrimoniais." Cf. PONTIFÍCIO CONSELHO PARA OS TEXTOS LEGISLATIVOS. Inst. Dignitas connubii (on-line) $<$ http://www.vatican. $\mathrm{va} /$ roman_curia/pontifical_councils/intrptxt/documents/rc_pc_intrptxt_doc_2005 0125_dignitas-connubii_po.html >. Acesso em 01/06/2017.

22 IOAN̄NES PAULUS PP. II, Alloc. ad Romanae Rotae tribunal, 20 ian. 2005, in Leges Ecclesiae post Codicem Iuris Canonici editae, ed. D. Andrés Gutiérrez, Vol. X, Roma, 2010, n. 6219, col. 165. Tendo presente a gravidade e a dificulda- 
Além de sólida preparação e formação permanente, uma decisão conforme a verdade requer, ainda, uma postura dialógica que a precede, também por parte daqueles que decidirão o mérito da causa. Por isso, não foi sem razão que a reforma operada pelo Papa Francisco manteve, também, a preferência por uma decisão colegial, como bem ressalta Arroba Conde:

La riforma conferma che la colegialità costituisce ordinariamente garanzia di qualità, non solo perché il cân. $1673, \S 3$ ribadisce sostanzialmente per la prima istanza quanto già previsto al cân. $1425, \S 1$, né perché il successivo $\S 5$ del cân. 1673 indica in modo espresso la forza irritante del requisito di collegialità in seconda istanza (norma specifica finora presente solo nella Dignitas connubiii). La ragione di maggior peso per trarre tale deduzione è quanto si afferma nel punto II del Proemio. In effetti, avvertendo che ora spetta al Vescovo - senza più bisogno di autorizazzione da parte della Conferenza episcopale decidere se affidare a un solo giudice le cause in prima istanza, si aggiunge che in tal caso al Vescovo stesse urge la responsabilità di evitare il pericolo di lassismo. L'unione tra rischio (pur involontario) di lassismo e formazione solo monocratica dell'organo giudiziale, con la corrispondente maggiore qualità che si presume nel giudice collegiale, giustifica che l'impossibilità di formare il collegio rimanga ancora come pressuposto necessario dell'eventuale affidamente della causa al giudice unico ${ }^{23}$.

de das causas de nulidade do matrimônio a Dignitas Connubii estabelece, no Art. 33, a necessidade de os Bispos curarem a formação de ministros idôneos da justiça para seus tribunais a fim de que os que forem eleitos para exercer tal ministério se dediquem a este múnus com diligência e segundo as normas do direito. Cf. PONTIFÍCIO CONSELHO PARA OS TEXTOS LEGISLATIVOS. Inst. Dignitas connubii (on-line) <http://www.vatican.va/roman_curia/ pontifical_councils/intrptxt/documents/rc_pc_intrptxt_doc_20050125_dignitasconnubii_po.html>. Acesso em 01/06/2017.

A respeito da formação dos ministros da justiça em geral, consultar a seguinte obra: C. IZZI, I ministri di giustizia in genere, in AAVV, Il giudizio di nulità matrimoniale dopo l'istruzione "Dignitas Connubii". Parte Seconda: La parte statica del processo, Libreria Editrice Vaticana, Città del Vaticano, 2007, pp. 103-130.

23 M. J. ARROBA CONDE - C. IZZI, Pastorale giudiziaria e prassi processuale nelle cause di nullità del matrimonio, pp. 56-57. 
Em síntese: a estrutura do processo judicial, como, também, a necessária preparação e qualificação dos operadores dos tribunais, somada à exigência de um pronunciamento colegial (esta é a regra e não a exceção), pretendem favorecer o necessário e sério discernimento judicial para que se chegue a uma decisão conforme a verdade, uma vez que misericórdia e verdade caminham de mãos dadas, tutelandose, desta forma, o vínculo matrimonial e o direito das pessoas a uma sentença justa.

Se o discernimento realizado em âmbito judicial se desenvolve, seguindo a estrutura e a dinâmica de um processo desta natureza, o qual está sujeito a uma série de exigências legais, o mesmo não ocorre com o não menos importante discernimento pastoral anterior ao processo do qual se ocuparia a Pastoral Judiciária. Aqui há uma enorme margem de liberdade para organizar este serviço, que, como aludido, teria por objetivo principal averiguar a existência, ou não, dos pressupostos necessários para se iniciar um processo canônico de nulidade do próprio matrimônio, como, também, preparar a causa.

É justamente a partir deste duplo objetivo que a Pastoral Judiciária se estruturaria e os cinco primeiros artigos das RPNM oferecem importantes indicações para isso, como se explicitará na sequência.

\subsection{A preparação remota da causa}

No Art. 1 das RPNM o Papa recorda que o Bispo, em virtude do cân. $383, \S 1$, está obrigado a seguir com ânimo apostólico os esposos separados ou divorciados que, pela sua condição de vida, tenham eventualmente abandonado a prática religiosa. Ele partilha com os párocos (cân. 529, § 1) a solicitude pastoral para com esses fiéis em dificuldade. Isso não significa que esta tarefa caiba exclusivamente aos Bispos e párocos, embora seja inegável que possuam uma responsabilidade maior. Em cada diocese e, particularmente, em cada paróquia, esta solicitude pastoral para com os fiéis em dificuldade é, na verdade, um compromisso no qual toda comunidade está, de uma forma ou de outra, implicada, embora efetivamente serão poucos a atuar diretamente neste serviço. Na $A L$, o Papa Francisco explicita a atitude que a comunidade eclesial deve ter em relação às pessoas divorciadas que vivem uma nova união: 
Quanto às pessoas divorciadas que vivem em uma nova união, é importante fazer-lhes sentir que fazem parte da Igreja, que "não estão excomungadas" e nem são tratadas como tais, porque sempre integram a comunhão eclesial. Estas situações exigem um atento discernimento e um acompanhamento com grande respeito, evitando qualquer linguagem e atitude que as faça sentir discriminadas e promovendo a sua participação na vida da comunidade. Cuidar delas não é, para a comunidade cristã, um enfraquecimento da sua fé e do seu testemunho sobre a indissolubilidade do matrimônio; antes, ela exprime precisamente neste cuidado a sua caridade ${ }^{24}$.

No contato com estes fiéis constata-se que o modo como reagem à própria situação é bem variado. Alguns continuam ligados à comunidade eclesial e participam intensamente de sua vida, atuando em diversas atividades, embora privados de uma prática sacramental plena, seguindo, desta forma, as orientações contidas no parágrafo terceiro do número 84 da $F C^{25}$. Outros, por sua vez, sentem-se marginalizados e participam da Igreja esporadicamente, como, por exemplo, por ocasião de um batizado, de um casamento ou de uma missa de sétimo dia. Há, também, os que se afastaram completamente da Igreja e mantêm uma postura crítica em relação a ela, sem, todavia, dela terem se desligado completamente por meio de um ato formal. Diante deste quadro variado de reações, a conversão pastoral à qual alude o Papa Francisco requer que a paróquia seja "comunidade de comunidades, santuário onde os sedentos vão beber para continuarem a caminhar, e centro de constante envio missionário" ${ }^{, 26}$. Para isso, urge que se vá criando na comunidade eclesial uma consciência a respeito da importância de se

24 FRANCISCUS PP., Adhortatio Apostolica Post-Synodalis Amoris Laetitia, $\mathrm{n}^{\circ}$ 243, p. 409.

25 Cf. IOANNES PAULUS PP. II, Adhortatio Apostolica Familiaris Consortio, n. 84, p. 185.

26 FRANCISCUS PP., Adhortatio Apostolica Evangelii Gaudium, n. 28, p. 1032. O documento 100 da CNBB é totalmente dedicado ao tema da conversão pastoral da paróquia vista como comunidade de comunidades. Cf. CONFERÊNCIA NACIONAL DOS BISPOS DO BRASI, Comunidade de comunidades: uma nova paróqua. A conversão pastoral da paróquia. Documentos da CNBB n ${ }^{\mathrm{o}} 100,5^{\mathrm{a}}$ ed., Paulinas, São Paulo, 2015. 
ir ao encontro de todos e, neste caso específico, daqueles que, talvez, a tenham abandonado parcialmente ou completamente por se sentirem marginalizados devido à situação matrimonial na qual se encontram. Este "sair de si" para "ir ao encontro de" requer discrição, respeito e coragem e faz parte daquela conversão pastoral da paróquia à qual alude o Romano Pontífice na $E G^{27}$. Como, de modo concreto, esta atitude de "saída" não é simplesmente uma questão de mero deslocamento geográfico, mas, sobretudo, de postura ou atitude, na qual se evidencia uma particular atenção para com os afastados, caberá a cada comunidade, em sintonia com o seu pároco e sob a orientação do Bispo diocesano, assumir este compromisso por meio de iniciativas bem concretas.

Como observa Arroba Conde, a um matrimônio que não prosperou se deve oferecer a possibilidade de uma revisão profunda dos seus pressupostos e, para isso, é preciso suscitar nos fiéis nele implicados uma disposição para se empenharem nesta revisão ${ }^{28}$. Seria, portanto, esta a tarefa daqueles que atuarão na preparação remota da causa no âmbito da pastoral ordinária. Faz parte deste primeiro momento, ir ao encontro das pessoas, acolhê-las e orientá-las. Isso não significa que todos serão automaticamente orientados a buscar um atendimento mais especializado (segundo momento deste discernimento pastoral) e que, por conseguinte, tudo irá terminar no tribunal eclesiástico com a apresentação do libelo introdutório da lide, pois, como é sabido, nem todo matrimônio que não prosperou está afetado pela nulidade.

No contato inicial com estes fiéis, ao acolhê-los e ouvi-los, é fundamental prestar atenção na existência, ou não, de dúvidas a respeito da validade do próprio matrimônio por parte deles, tendo-se o cuidado, na análise dos casos, de evitar duas posturas radicais: o laxismo e o rigorismo. A primeira vê a nulidade em tudo e a segunda não enxerga a nulidade em caso algum. Para favorecer esta acolhida, discernimento e orientação inicial, talvez seja útil a oferta de palestras, encontros e cursos diversos (breves) por meio dos quais se proporcio-

27 FRANCISCUS PP., Adhortatio Apostolica Evangelii Gaudium, n. 30, p. 1032.

28 Cf. M. J. ARROBA CONDE - C. IZZI, Pastorale giudiziaria e prassi processuale nelle cause di nullità del matrimonio, p. 35. 
ne aos clérigos ${ }^{29}$, consagrados e leigos, particularmente aos que atuam na pastoral familiar paroquial, uma formação elementar a respeito da compreensão do matrimônio em seus diversos aspectos, destacandose, evidentemente, o jurídico. Faz-se mister um conhecimento, ao menos básico, dos requisitos exigidos para a validade do matrimônio e dos motivos que possam gerar a sua nulidade, como, também, dos caminhos possíveis para com ela se lidar. Sem este conhecimento básico por parte dos agentes pastorais pouco se poderá avançar na preparação remota da causa.

Se nas diversas comunidades, as pessoas separadas, divorciadas e que vivem em uma nova união tivessem a possiblidade de manter contato com quem lhes possa acolher, ouvir atentamente e ajudar a averiguar a existência, ou não, dos pressupostos necessários para se iniciar um processo canônico de nulidade do próprio matrimônio; se, conforme o caso, tais pessoas pudessem ser informadas e orientadas a respeito da existência de um serviço especializado, voltado especificamente para um discernimento mais profundo a respeito da própria situação matrimonial deste um ponto de vista jurídico, tornar-se-ia, então, realidade a solicitude pastoral para com esses fiéis em dificuldade à qual se refere o Art. $1^{\circ}$ das RPNM e o objetivo deste primeiro momento seria alcançado.

29 Em relação ao clero, o cân. 279 se ocupa da sua formação permanente e faz referência explícita à participação em palestras e eventos que contribuam para esta formação. Sendo assim, seria de grande valia incluir na organização destes eventos formativos temas que ajudassem no serviço àqueles que se encontram na condição de separados, divorciados e em nova união. Além disso, para os futuros ministros ordenados, se poderia inserir na formação filosófico-teológica e atuação pastoral ligada a este período, certos conteúdos e práticas diretamente conexos com a questão da nulidade do matrimônio e do processo a ela correspondente.

Em relação aos leigos, o cân. 229, § 1 reafirma o direito/dever dos leigos de adquirir um conhecimento da doutrina cristã que lhes propicie anunciá-la e defendê-la, como, também, participar no exercício do apostolado. O cân. 231, § 1 assevera que os leigos destinados permanente ou temporariamente a um serviço especial na Igreja têm a obrigação de adquirir a formação requerida para o cumprimento do próprio encargo e para exercê-lo consciente, dedicada e diligentemente. 


\subsection{A investigação pré-judicial (preparação imediata)}

No Art. 2 das RPNM o Papa Francisco faz referência a uma investigação pré-judicial ou pastoral. Tratar-se-ia aqui de algo mais especializado, diferente do primeiro momento ao qual se aludiu, pois tal investigação teria por foco a preparação imediata da causa. Nela seriam realizadas algumas ações explicitadas nas RPNM por dois verbos: conhecer e recolher. Eis o texto:

Art. 2. A investigação pré-judicial ou pastoral, que acolhe nas estruturas paroquiais ou diocesanas os fiéis separados ou divorciados que duvidam da validade do próprio matrimônio ou estão convictos de sua nulidade, tem por fim conhecer a sua condição e recolher elementos úteis para eventual celebração do processo judicial, ordinário ou mais breve. Tal investigação desenvolver-se-á no âmbito da pastoral matrimonial diocesana unitária.

Como organizar este serviço?

Partindo-se da realidade de muitas paróquias, particularmente no Brasil, é pouco provável que em cada uma delas seja criado um serviço especializado que dê conta desta investigação pré-judicial, voltada para a preparação imediata da causa. Embora não seja uma atividade de natureza judiciária, mas, sim, pastoral, é inegável que possui uma conexão com o judiciário, uma vez que estaria voltada para um discernimento que poderá redundar na decisão de se recorrer ao processo judicial de declaração de nulidade do matrimônio, seja ele documental, ordinário ou mais breve, recolhendo-se, de antemão, os elementos necessários para que isso ocorra e culminando com a apresentação do libelo junto ao tribunal eclesiástico competente.

Considerando a realidade circundante, talvez seja mais realista e adequado integrar este serviço à Pastoral Familiar em âmbito diocesano, sem excluir que determinadas paróquias até possam se organizar para isso, realizando o processo em todas as suas etapas, caso realmente tenham condições de fazê-lo. Todavia, a simples criação de um departamento ou de qualquer estrutura análoga que funcione exclusivamente na Cúria Diocesana, tendo os fiéis que a ela se dirigir para ali serem atendidos ou orientados neste discernimento pastoral, poderia 
não representar um grande passo, embora seja algo bem mais simples de ser feito, talvez até como um primeiro passo. Isso porque em muitos países e, particularmente no Brasil, as dioceses são formadas territorialmente por algumas cidades, cuja distância entre elas e a sede da diocese não favorece o deslocamento das pessoas para receberem este atendimento durante o horário do expediente curial. Não se pode ignorar, também, que as inúmeras ocupações e preocupações das pessoas, muitas vezes envolvidas com o trabalho e a "correria do dia-a-dia", costumam ser um obstáculo para este deslocamento. Como nem sempre a preparação da causa se daria em um único encontro, as pessoas teriam que retornar mais de uma vez, o que não deixa de ser uma dificuldade para aqueles que residem distantes da sede da diocese. Por conseguinte, parece estar mais em conformidade com a ideia de uma "Igreja em saída" que este o serviço pudesse ser levado às pessoas lá onde elas se encontram, e não o inverso. Sendo um serviço "itinerante", nele estaria implicado um deslocamento geográfico e isso teria, também, os seus inconvenientes. Não há como deixar de reconhecer que se trata de uma proposta bem mais exigente, o que requer uma boa dose de ousadia e criatividade, com os riscos normais de acertos e erros.

Em linha de princípio, este serviço diocesano de atendimento aos fiéis não estaria vinculado diretamente às Câmaras Eclesiásticas no sentido de ser realizado pelas mesmas pessoas que nela atuam, particularmente pelos auditores, embora até possam participar da formação e acompanhamento dos agentes que atuariam nesta pastoral. $\mathrm{O}$ Art. 23, § 2 da instrução Dignitas Connubii $(D C)$ considera a Câmara Eclesiástica como uma seção de instrução processual (e de fato o é), formada por um ou mais auditores e um notário com o intuito de recolher as provas e notificar os atos processuais ${ }^{30}$. Ora, sendo a Câmara

30 O Decreto de Constituição e Normas dos Tribunais Eclesiásticos Regionais no Brasil, da Presidência da CNBB, entrado em vigor aos 02 de junho de 1974, estabelecia a possibilidade de se constituir ou confirmar câmaras auxiliares permanentes nas sedes diocesanas. Posteriormente, em 1986, foram aprovadas, na $24^{\mathrm{a}}$ Assembleia Geral dos Bispos do Brasil, as Normas para os Tribunais Eclesiásticos Regionais e Interdiocesanos do Brasil. O capítulo II das normas aprovadas é dedicado às câmaras eclesiásticas. Algum tempo depois, Guimarães fez um interessante estudo a respeito das câmaras eclesiásticas vistas por ele como um ins- 
Eclesiástica uma estrutura ligada ao judiciário da Igreja, os que nela atuam pertencem a esta estrutura, razão pela qual não é aconselhável que prestem este serviço, pois não convém misturar o discernimento pastoral, prévio ao processo, com o discernimento judicial, que já é parte do processo. Em outras palavras, parece não ser muito adequado que o auditor atue diretamente na Pastoral Judiciária, tratando diretamente com pessoas que, mais adiante, poderão estar diante dele na condição de parte demandante ou demandada durante a instrução da causa $^{31}$. O discernimento judicial exige a imparcialidade em todas as fases de tramitação da causa, que poderia ficar comprometida justamente no "coração" do processo, ou seja, em sua instrução ${ }^{32}$, afetando, assim, a decisão de mérito a ser tomada na sentença. Não raramente se recorre às "carências" existentes no judiciário da Igreja para se proceder de outra forma, o que é perfeitamente compreensível, mas, sem dúvida, não é o ideal.

Os que atuariam neste serviço necessitariam de uma preparação (cânn. 229, § 1 e 231, § 1). Portanto, o desafio consistiria em formar (curso e práxis) e acompanhar (avaliação e supervisão) os agentes pastorais dispostos a se deslocar em missão (itinerância), visitando as diversas cidades (regiões/áreas) no âmbito do território de cada diocese, a partir de um cronograma pré-estabelecido. Como já observado, tratase de uma proposta um pouco mais ousada, a não ser que se optasse

trumento muito válido e útil para a nossa realidade brasileira. Cf. J. F. GUIMARÃES, As Câmaras Eclesiásticas: agilização da justiça eclesiástica, in Revista Direito \& Pastoral, Ano VII, julho-setembro de 1993, n² 27, pp.31-38.

31 O Art. 113, §§ 1-2 da instrução Dignitas Connubii prevê um serviço de assessoria canônica no âmbito do próprio tribunal eclesiástico. Todavia, veta a participação na causa, como juízes e defensores do vínculo, daqueles que atuam neste serviço. As razões são as mesmas já invocadas aqui para desaconselhar que isso venha a ocorrer nas câmaras eclesiásticas. Além disso, a Pastoral Judiciária, objeto deste estudo, vai bem mais além deste serviço ao qual se refere este artigo citado.

32 O cân. 1428, § 3 atribui ao auditor particulares poderes. Seguramente não se trata apenas de um mero executor de um questionário pré-estabelecido. Para um estudo a respeito desta figura, consultar a seguinte obra: L. GHISONI, I ministri di giustizia in specie: uditori e assessori, in AA.VV, Il giudizio di nullità matrimoniale dopo l'istruzione Dignitas Connubii, Libreria Editrice Vaticana, Città del Vaticano, 2007, pp. 157-175. 
por simplesmente criar uma estrutura fixa na Cúria Diocesana para onde os fiéis interessados teriam que se dirigir. Nestas visitas, ofertarse-ia este serviço especializado às paróquias que, por sua vez, poderiam ser agrupadas por vicariatos forâneos, setores, regiões, etc. Esta forma de atuar, ou seja, ir ao encontro das pessoas e não esperar que venham até a Cúria, levando, assim, o serviço até elas e não o contrário, talvez produza bons frutos nesta fase anterior ao processo judicial na qual se encontra situada a Pastoral Judiciária. Os fiéis que inicialmente já mantiveram nas diversas comunidades de pertença um primeiro contato com alguém que os acolheu e orientou a procurar este serviço (quando fosse o caso), seriam, agora, devidamente informados a respeito da presença de tais agentes nos locais indicados. Com eles se encontrariam para esta investigação pastoral que poderá culminar, ou não, com a decisão de pedir a declaração de nulidade do próprio matrimônio por meio da apresentação do libelo introdutório da lide, uma vez que a impugnação do matrimônio cabe, primeiramente, aos cônjuges, tal como reafirmado pelo $M I D I$ (cân. 1674, § 1, $1^{\circ}$ ).

Quem seriam os agentes que atuariam neste serviço?

O Art. 3 das RPNM assim estabelece:

\begin{abstract}
Art. 3. A mesma investigação será confiada a pessoas consideradas idôneas pelo Ordinário do lugar, dotadas de competências, ainda que não exclusivamente jurídico-canônicas. Dentre elas estão, em primeiro lugar, o pároco próprio ou o que preparou os cônjuges para a celebração das núpcias. Esta tarefa de consultoria pode ser confiada também a outros clérigos, consagrados ou leigos aprovados pelo Ordinário do lugar.
\end{abstract}

Embora o texto afirme que esta investigação pré-judicial possa ser confiada em primeiro lugar ao pároco próprio ou a quem preparou os cônjuges para a celebração das núpcias, isso não equivale a afirmar que não possa ser realizada por outras pessoas (clérigos, consagrados ou leigos aprovados pelo Ordinário do lugar) dotadas de competências, ainda que não exclusivamente jurídico-canônicas, como o próprio texto admite. Considerando o quanto afirmado pelo Art. 2 das RPNM, trata-se de uma investigação que visa conhecer a condição dos fiéis separados ou divorciados que duvidam da validade do próprio matrimônio ou estão convictos de sua nulidade, como, também, reco- 
lher elementos úteis para a eventual realização do processo de nulidade matrimonial, ordinário ou mais breve. Sendo assim, em se tratando de preparação imediata da causa, parece suficientemente claro que a idoneidade para este serviço não é dada pelo fato de alguém ser detentor deste ou daquele ofício na Igreja, mas, sim, pela qualificação, embora não necessariamente acompanhada por uma titulação, uma vez que não se está no âmbito do poder judiciário no qual se exige para determinados ofícios a titulação e a qualificação.

Dentre os possíveis agentes desta Pastoral Judiciária, particularmente neste segundo momento, Arroba Conde destaca três figuras a respeito das quais é preciso dizer algo: o psicólogo, o mediador e o advogado ${ }^{33}$.

A ajuda de um psicólogo, desde que comprometido com uma antropologia em harmonia com a visão cristã do homem ${ }^{34}$, poderia auxiliar a pessoa interessada em impugnar o matrimônio a realizar uma análise objetiva da própria experiência conjugal, caindo na conta de que a sua percepção subjetiva dos fatos relativos a esta experiência nem sempre equivale à realidade. Além disso, para muitos, enfrentar o processo de nulidade matrimonial significa, também, colocar-se em jogo, reabrir as feridas do passado, envolver a outra parte e outras pessoas que conheceram os fatos, o que não é uma tarefa fácil. Portanto, o necessário apoio psicológico talvez seja um suporte válido para a pessoa enfrentar o processo de nulidade matrimonial com lucidez e força

33 Cf. M. M. J. ARROBA CONDE - C. IZZI, Pastorale giudiziaria e prassi processuale nelle cause di nullità del matrimonio, pp. 36-46.

34 Embora não se esteja aqui no âmbito do processo judicial, é importante que o psicólogo que atuará neste serviço esteja comprometido com uma antropologia em harmonia com a visão cristã do homem. Caso posteriormente seja chamado a atuar no processo judicial, quer como perito privado, quer como perito judicial, a avaliação judicial da perícia por ele produzida necessariamente levará em conta este dado. O Magistério Pontifício chamou a atenção sobre isso em algumas ocasiões. Cf. IOANNES PAULUS PP. II, Allocuzione alla Rota Romana, 05.02.1987, in $A A S, 79$ (1987), pp. 1453-1459; IOANNES PAULUS PP. II, Allocuzione alla Rota Romana, 25.01.1998, in AAS, 80 (1988), pp. 1178-1185. Para um estudo da jurisprudência relativa a estes pronunciamentos do Papa sobre o tema, cf. C. IZZI, Valutazione del fondamento antropologia dela perizia. Studio sulla recente giurisprudenza rotale in tema d'incapacità consensuale, Quaderni di Apollinaris, Lateran University Press, Roma, 2004. 
interior. Este suporte psicológico poderia, também, preparar uma futura reconciliação entre as partes, não no sentido de levá-las a reatar a união conjugal (o que não pode ser descartado), mas, ao menos, no sentido de tentar envolvê-las neste discernimento pré-judicial. Arroba Conde assevera que nada impediria que desse acompanhamento resultasse um parecer psicológico, a ser anexado pelo interessado ao libelo introdutório da lide, quando resultar útil para o esclarecimento dos fatos relativos à nulidade ${ }^{35}$.

A presença de um mediador teria o intuito de favorecer a compreensão adequada do contraditório processual, suscitando na pessoa interessada uma disposição para incluir a outra parte neste discernimento. É preciso deixar bem claro qual é o significado de uma causa de nulidade matrimonial e o quanto a participação dos cônjuges é fundamental para a busca da verdade, tendo em vista uma decisão justa. A história conjugal tem por protagonista as partes e não apenas uma delas. Se a outra parte aceitasse dialogar com o mediador, oferecendo informações que entenda ser importantes para o esclarecimento dos fatos, isso seria de grande valia. Se após uma análise serena da história do próprio matrimônio surgisse uma convergência entre as partes nele implicadas, não apenas em relação a uma possível nulidade, mas, sobretudo, em relação aos fatos que a teriam gerado, ter-se-iam as premissas para a apresentação do litisconsortio ativo ${ }^{36}$, como, também, se

35 Cf. M. J. ARROBA CONDE - C. IZZI, Pastorale giudiziaria e prassi processuale nelle cause di nullità del matrimonio, pp. 36 .

36 A apresentação conjunta do libelo é uma possibilidade já prevista pelo Art. 102 da instrução Dignitas Connubii. Quando isso ocorre, verifica-se o "litisconsorzio ativo". Arroba Conde esclarece que não se trata de uma mera conformidade da parte demandada com o pedido da parte demandante, pois, na verdade, se permite que ambos sejam autores da ação. Infelizmente, falta a coordenação desta norma com as demais, pois na compreensão da participação dos cônjuges no processo, um aparece como parte demandante e outro como parte demandada. Coordenar o "litisconsorzio ativo" com as demais normas não é algo impossível, mas obriga a distinguir entre a coincidência entre a vontade das partes (ambas querem a nulidade do matrimônio e a solicitam) e a coincidência da versão dos fatos apresentados por elas, que dizem respeito a uma experiência de insucesso pessoal e interpessoal da qual, raramente, possuem uma posição unívoca e compartilhada. Neste sentido, o "litisconsorzio ativo", segundo o autor, não deve diminuir a dialética processual, seja entre as partes e o defensor do vínculo, seja, 
cumpriria um dos requisitos fixados por lei para a realização do processo mais breve $\mathrm{e}^{37}$. Caso as partes participassem desta fase prévia ao processo, a parte demandada não seria surpreendida com um libelo que não raramente nela produz um descontentamento que acaba por provocar a sua ausência ou, então, uma tomada de posição que dá ao processo um caráter belicoso. Na primeira hipótese, se correria o risco de um processo com a visão de uma só parte (o que não é bom para o contraditório processual); na segunda hipótese, a celeridade processual poderia ficar prejudicada pela apresentação de incidentes com o intuito de prolongar ao máximo a duração da causa. Tentar suscitar nas partes, já a partir desta fase pré-processual, uma atitude dialógica e colaborativa traria um enorme ganho para o processo, tanto na questão de mérito, quanto na questão de sua agilidade e celeridade, razão pela qual a atuação de um mediador é algo a ser valorizado e incentivado. À figura do advogado, faz menção o Art. 4 das RPNM ${ }^{38}$ :

Art. 4 A investigação pastoral recolhe os elementos úteis para a eventual introdução da causa por parte dos cônjuges ou de seu patrono $^{39}$ perante o tribunal competente. Indague-se se as partes estão de acordo em pedir a nulidade.

também, entre os próprios cônjuges. M. J. ARROBA CONDE, Diritto processuale canonico, $6^{\mathrm{a}}$ ed., Ediurcla, Roma, 2012, pp.347-348.

37 Para um estudo do processo mais breve consultar: AAVV, La riforma dei processi matrimoniali di Papa Francesco: una guida per tutti, pp. 9-27; M. J. ARROBA CONDE - C. IZZI, Pastorale giudiziaria e prassi processuale nelle cause di nullità del matrimonio, pp. 137-173; V. J. RIBEIRO, A reforma do processo de nulidade matrimonial, pp. 141-169.

38 O serviço dos advogados é um verdadeiro ministério na Igreja e possui uma deontologia específica (cânn. 1488-1489 e Artt. 110 e 111 da instrução Dignitas Connubii). Para conhecer os seus deveres, particularmente na fase prévia ao processo, conferir: M. J. ARROBA CONDE, Principi di deontologia forense canônica, in AAVV, Il diritto di difesa nel processo matrimoniale canônico, Libreria Editrice Vaticana, Città del Vaticano, 2006, pp. 138-140.

39 O cân. 1490 faz menção aos "patronos estáveis". Trata-se de um termo genérico que engloba duas funções: procurador e advogado. $\mathrm{O}$ primeiro, age no processo em nome da parte que representa, exprimindo qual é a vontade do representado em cada ato processual. O segundo, presta uma assistência técnica à parte, mas não a representa, exercendo a sua função em seu próprio nome, embora em favor daquele a quem assiste. Não raramente uma mesma pessoa ocupa as duas funções. No texto acima citado, o Papa Francisco utiliza o termo "patrono". O utili- 
É preciso distinguir entre o patrono (advogado com formação canônica) que atuará em âmbito judicial canônico e a figura do advogado que atuaria na Pastoral Judiciária. Para atuar em âmbito judicial canônico, é preciso se ater aos requisitos fixados pelo cân. 1483. É fundamental ter presente que a responsabilidade institucional do advogado canônico é enorme. Não se trata de mera transposição de sua função em âmbito civil para o âmbito eclesial ${ }^{40}$. Já na Pastoral Judiciária, é possível recorrer a alguém com conhecimento jurídico canônico, mas sem a devida titulação, podendo, ou não, ter alguma atuação ou experiência no judiciário civil. Evidentemente facilitaria muito as coisas se fosse a mesma pessoa a atuar nas duas fases (antes e durante o processo), caso preencha os requisitos para isso. Caberia ao advogado canônico auxiliar na preparação imediata da causa. Aqui seriam recolhidos os elementos úteis para a sua introdução e o seu prosseguimento, como, por exemplo, o levantamento de nomes daqueles que acompanharam a história conjugal (familiares, parentes e amigos) e que possam, de fato, oferecer informações bem concretas a respeitos dos fatos conexos com a nulidade; a coleta de documentos diversos (cartas, e-mails, fotos, vídeos, documentos clínicos, atestados diversos, etc.) que, posteriormente, possam ser propostos como prova, cabendo ao juiz admiti-los, ou não ${ }^{41}$. Seria, também, função do advogado ca-

zaremos no sentido de "advogado canônico", sem excluir que tenha, também, a função de procurador.

40 Com relação ao papel institucional do advogado canônico e de sua corresponsabilidade, conferir: M. J. ARROBA CONDE - C. IZZI, Pastorale giudiziaria e prassi processuale nelle cause di nullità del matrimonio, pp. 38-46.

41 A investigação prévia e o renovado empenho para uma preparação bem acurada da causa, antes mesmo da introdução do libelo e início do processo, poderia suscitar o temor de um prejuízo para a prova estritamente judicial, viciando, de certa forma, o processo, pois as causas já chegariam aos tribunais com diagnósticos e soluções prontas. Para Arroba Conde este risco, como qualquer outro erro decorrente das normas vigentes até o $M I D I$, depende fundamentalmente da formação adequada dos operadores do direito, particularmente do instrutor da causa, de quem se espera uma atuação centrada sobre os fatos e suas circunstâncias, inclusive daqueles fatos comprovados de modo provisório na fase de preparação da causa. Cabe a ele apurar o quando, como, onde e o porque de cada fato relevante na causa, de modo a reconstruir da melhor forma possível a história do matrimônio em análise no âmbito do processo judicial. Cf. M. J. ARROBA CONDE - C. 
nônico auxiliar a pessoa na elaboração do libelo introdutório da lide, uma vez que esta investigação prévia se conclui com o libelo, tal como prevê o Art. 5 das RPNM.

Concluída a abordagem relativa aos cinco artigos da RPNM que se ocupam da Pastoral Judiciária, valeria a pena retomar alguns elementos que se aconselha levar em conta na estruturação deste serviço, particularmente com relação ao seu segundo momento (a investigação pré-judicial): formação, itinerância, limites, desafios e atitude fundamental $^{42}$.

\section{a) Formação}

A formação dos que atuarão neste serviço (clérigos, consagrados e leigos) é algo imprescindível. Para a preparação remota da causa, seria suficiente a oferta de palestras, encontros e cursos diversos (breves) por meio dos quais se proporcionaria aos clérigos, consagrados e leigos, particularmente aos que atuam na pastoral familiar, uma formação elementar a respeito da compreensão do matrimônio em seus diversos aspectos, destacando-se, o jurídico. Para a preparação imediata da causa (investigação pré-judicial) se requer, de antemão, a estruturação de um curso ou algo do gênero no qual haja uma combinação entre teoria e prática, avaliação e supervisão, e se tenha por norte a dimensão jurídica do matrimônio (aspectos substantivos e processuais), uma vez que este serviço estaria voltado especificamente para a questão da nulidade do matrimônio. Sem isso, como conhecer realmente a condição dos fiéis separados ou divorciados que duvidam da validade do próprio matrimônio ou dela estão convictos? Como recolher os elementos úteis para a eventual celebração do processo judicial, ordinário ou mais breve? Como preparar a causa para que o processo seja célere e se apresente o contraditório processual de maneira correta? Aqui não se pode improvisar. Combinando formação, avaliação e supervisão, inseridas no organograma da Pastoral Familiar, estariam

IZZI, Pastorale giudiziaria e prassi processuale nelle cause di nullità del matrimonio, p. 38.

42 Para um estudo a respeito de alguns destes elementos tomados por referência, conferir: AAVV, La riforma dei processi matrimoniali di Papa Francesco: una guida per tutti, pp. 9-27. 
plantadas as bases para um serviço que possa ser eficiente e eficaz. Seria um grande passo se as faculdades e os institutos superiores de direito canônico entrassem neste projeto, estabelecendo-se uma espécie de parceria com as diversas dioceses, cabendo a tais instituições a responsabilidade de assumir ou auxiliar nesta formação dos agentes ligados à Pastoral Familiar.

O foco predominantemente jurídico desta formação não significa, em absoluto, desconhecer ou ignorar as diversas dimensões do matrimônio (antropológica, teológica, moral, psicológica, sociológica, espiritual, etc.), que precisariam ser levadas em conta nesta formação (o jurídico também as leva), mas não é realista ter um serviço que queira se ocupar e resolver tudo. É bom lembrar que a Pastoral Judiciária se situa no âmbito da Pastoral Familiar e, portanto, os diversos aspectos ou dimensões do matrimônio precisariam ser integrados na Pastoral Familiar como um todo.

\section{b) Itinerância}

Quanto à itinerância, na perspectiva de uma "Igreja em saída", seria pouco provável que tudo se resolvesse em um primeiro encontro entre a pessoa interessada e os agentes pastorais, pois nesta fase préprocessual é preciso levar adiante um discernimento que poderá resultar, ou não, na decisão de se iniciar uma causa a ser ainda preparada. Isso requer alguns encontros, cujo número e duração dependeriam de cada caso, respeitando-se a singularidade de cada pessoa que se apresenta para este discernimento. Não se devem multiplicar em demasia tais encontros, por questões diversas, começando pelo número de agentes disponíveis (inicialmente, talvez não sejam tantos assim) e pela necessidade de se atender ao maior número possível de pessoas. Além do mais, não se deve ignorar que os agentes de pastoral, particularmente os leigos, possuem outras obrigações, dentre as quais as familiares, que exigem a sua presença no lar. Não é tão fácil ter um grupo de pessoas que se disponha (não raramente seria nos finais de semana) a percorrer as diversas cidades que formam o território de uma diocese, ou as diversas regiões ou áreas pastorais, para oferecer orientações e a ajuda necessária para este discernimento pastoral prévio ao processo de nulidade matrimonial. Se não houvesse esta itinerância e 
se criasse uma estrutura na Cúria Diocesana, este problema obviamente não existiria, mas, em contrapartida, se perderia a chance de se levar este serviço até as pessoas e não o contrário.

\section{c) Limites}

Este serviço, como qualquer outro, teria os seus limites e é preciso ter consciência disso, evitando-se iludir a si e aos demais. O processo de nulidade matrimonial não é a única e nem a principal solução para o fenômeno da separação e do divórcio, como se fosse uma espécie de "poção mágica" que solucionaria todos os problemas que afetam as relações interpessoais e conjugais. Tanto é verdade, que não raramente os que conseguem obter a declaração de nulidade do matrimônio anterior entram em uma nova experiência conjugal que também não prospera. Isso revela que pouco resolve o recurso ao judiciário da Igreja para a solução de problemas cuja raiz não é de natureza jurídica, embora tenha repercussões e relevância jurídicas, como é o caso da nulidade. Daí reforça-se a importância da integração deste serviço no âmbito maior da Pastoral Familiar. As pessoas que fizeram a experiência de um matrimônio que não prosperou, seja ele nulo ou não, talvez necessitem de um acompanhamento que lhes permita, à luz da fé e de um amadurecimento humano e cristão, uma séria e serena reelaboração da experiência vivida no matrimônio anterior ${ }^{43}$. Fechar os olhos para isso e focar apenas e tão somente na questão jurídica da nulidade seria insuficiente.

Um segundo limite a considerar é que a existência dos pressupostos para se iniciar uma causa de nulidade em um tribunal eclesiástico não equivale a uma sentença de nulidade. Embora este serviço possa favorecer o aumento no número de pessoas que ingressarão com um pedido de impugnação do próprio matrimônio, nem todos conseguirão obter o que desejam. Isso porque nem todo matrimônio que não foi adiante é nulo e não existe um matrimônio válido que, depois, se

43 É por isso que o Papa Francisco na $A L$ chama a atenção para a importância de uma pastoral da reconciliação e da mediação, inclusive através de centros de escuta especializada. Cf. FRANCISCUS PP., Adhortatio Apostolica PostSynodalis Amoris Laetitia, nº 242, p. 409. 
torna nulo. A nulidade deve se fazer presente no momento do consentimento, pois é o consentimento a causa eficiente e formal de qualquer matrimônio, seja ele sacramental ou não, sem ignorar a possiblidade de nulidade por inabilidade jurídica ou defeito de forma canônica. Portanto, é preciso ter a consciência de que a possibilidade de se entrar com um processo de nulidade não garante, por si só, uma resposta afirmativa ao quanto pleiteado e, caso isso ocorra, há, ainda, a possibilidade da imposição de um veto, dependendo do problema que teria dado origem à nulidade do matrimônio.

\section{d) Desafios}

É preciso estar ciente de que algumas pessoas possuem uma imagem negativa dos processos canônicos, vistos por elas como algo complexo, longo, custoso, fatigoso, doloroso e de êxito incerto. Para elas optar pelo processo de nulidade matrimonial significa colocar-se em jogo, reabrir as feridas do passado, envolver a outra parte e outras pessoas que conheceram os fatos. Isso não é uma tarefa fácil, razão pela qual muitos desistem ou sequer cogitam a ideia de entrar com um processo do gênero. Será um desafio ajudar as pessoas a perceberam que a imagem que se fazem dos processos canônicos pode não corresponder à realidade. Uma boa orientação nesta fase pré-judicial ajudaria a assentar as bases para um desenvolvimento célere e sereno do processo judicial. Além disso, como observado, o recurso ao processo de nulidade matrimonial não garante uma sentença nula e, caso isso ocorra, ou, então, haja um veto para contrair novas núpcias, será necessário colocar-se ao lado das pessoas, ajudando-as a lidar com esta situação e com os limites que dela decorrem.

\section{e) Atitude fundamental}

Na Igreja todos os que participam do processo de nulidade matrimonial possuem a obrigação de buscar a verdade, assumindo uma posição dialógica e oferecendo a própria contribuição para que isso ocorra. Na busca desta verdade, é fundamental uma atitude de abertura, de diálogo, como, também, o devido senso crítico para perceber que nem sempre a percepção subjetiva dos fatos corresponde à reali- 
dade dos fatos. Faz parte desta abertura o estar disposto a assumir com a devida responsabilidade as consequências, tanto positivas quanto negativas, que decorrem desta análise. Se, de fato, há diversos cônjuges separados que após uma atenta análise da própria história conjugal chegarão à conclusão a respeito da nulidade do seu próprio matrimônio, haverá, também, os que, à luz de um sério discernimento, concluirão que não houve a nulidade e, portanto, precisarão assumir esta verdade com as suas consequências e será necessário ajudá-los nisso. Seria contrário à verdade e à caridade alimentar nas pessoas expectativas desproporcionais e ilusórias. Nunca é demais recordar que o Papa Francisco manteve a opção pelo processo judicial, justamente porque é a via mais adequada para a busca da verdade e para a tutela dos direitos subjetivos dos fiéis e do sagrado vínculo do matrimônio.

\section{Considerações finais}

A implantação da Pastoral Judiciária, a partir do quanto proposto aqui, poderá parecer algo inviável, particularmente quando se adota por parâmetro a realidade de alguns tribunais eclesiásticos e suas carências. É sabido que não poucos tribunais funcionam com uma estrutura precária e padecem de recursos de toda ordem para levar adiante um serviço célere e de qualidade. Se, na prática, o funcionamento dos tribunais eclesiásticos ainda está aquém do ideal, será que a implantação de uma Pastoral Judiciária "itinerante", que requer formação, acompanhamento e deslocamento dos agentes pastorais, encontraria condições mais favoráveis? É possível que sim, pois, diferentemente do que ocorre com as estruturas judiciárias da Igreja, não há uma normativa que rege a estruturação desta Pastoral e nem a exigência de títulos acadêmicos.

É importante ter presente que caso a Pastoral Judiciária seja efetivamente implantada e funcione a contendo, provavelmente haveria um aumento significativo no número de pedidos de nulidade. Neste caso, os tribunais eclesiásticos precisariam ser reforçados para oferecerem um serviço célere e de qualidade, pois, do contrário, aumentaria o número de processos e se correria o risco de se retardar ainda mais a solução dos casos submetidos ao judiciário da Igreja. Não foi sem motivo que o Papa Francisco pensou na constituição de tribunais dioce- 
sanos, lembrando, porém, que se trata de uma estrutura que requer a presença de pessoas com titulação e qualificação, razão pela qual investir na formação de novos canonistas, clérigos, religiosos (as) e leigos (as), seria tão urgente quanto a implantação da Pastoral Judiciária.

Por fim, o desafio está lançado e colocado. Caberá ao Bispo diocesano, com o apoio do seu presbitério, particularmente dos párocos, dar os primeiros passos na direção da criação deste serviço, inserido no âmbito da Pastoral Familiar, no qual direito e pastoral se encontram e, deste encontro, poderão surgir muitos frutos, contribuindo, assim, para que a reforma proposta pelo Papa Francisco possa lograr o êxito almejado.

\section{BIBLIOGRAFIA}

\section{Fontes}

FRANCISCUS PP., Adhortatio Apostolica Post-Synodalis Amoris Laetitia [=AL], in $A A S, 108$ (2016), pp. 311-446.

, Adhortatio Apostolica Evangelii Gaudium, in AAS, 105 (2013), pp. 1019-1137.

, Litterae Apostolicae Motu proprio datae Mitis et Misericors Iesus quibus canones Codex Canonum Ecclesiarum Orientalium de Causis ad Matrimonii nullitatem declarandam reformantur, in AAS, 107 (2015), pp. 946-957.

, Litterae Apostolicae Motu proprio datae Mitis Iudex Dominus quibus canones Codicis Iuris Canonici de Causis ad Matrimonii nullitatem declarandam reformantur, in $A A S, 107$ (2015), pp. 958-970.

IOANNES PAULUS PP. II, Adhortatio Apostolica Familiaris Consortio, in $A A S, 74$ (1982), pp. 81-191.

, Alloc. ad Romanae Rotae tribunal, 20.01.2005, in Leges Ecclesiae post Codicem Iuris Canonici editae, ed. D. Andrés Gutiérrez, Vol. X, Roma, 2010, n. 6219, col. 165. 
, II. Allocuzione alla Rota Romana, 05.02.1987, in AAS, 79 (1987), pp. 1453-1459.

, II. Allocuzione alla Rota Romana, 25.01.1998, in AAS, 80 (1988), pp. 1178-1185.

JOÃO PAULO II, Codex Iuris Canonici, Promulgado aos 25/01/1983. Tradução oficial: Conferência Nacional dos Bispos do Brasil, Loyola, São Paulo, 2017.

PONTIFICIO CONSELHO PARA OS TEXTOS LEGISLATIVOS. Inst. Dignitas connubii <http://www.vatican.va/roman_curia/ pontifical_councils/intrptxt/documents/rc_pc_intrptxt_doc_2005 0125_dignitas-connubii_po.html $>$. Acesso em 01/06/2017.

SÍNODO DOS BISPOS. III Assembleia geral extraordinária do Sínodo dos Bispos: Os desafios pastorais sobre a família no contexto da evangelização (on-line) <http://www.vatican.va/roman curia/synod/documents/rc_synod_doc_20141018_relatio-ynodifamilia_po.html $>$ Acessado aos 30/06/2017.

,XIV Assembleia geral ordinária: A vocação e a missão da família na Igreja e no mundo contemporâneo (on-line) $<$ http://www.vatican.va/roman_curia/synod/documents/rc_synod _doc_20151026_relazione-finale-xiv-assemblea_po.html >. Acessado aos 30/05/2017.

CONFERÊNCIA NACIONAL DOS BISPOS DO BRASIL, Comunidade de comunidades: uma nova paróqua. A conversão pastoral da paróquia, Documentos da CNBB 100, 5 a edição, Paulinas, São Paulo, 2015.

, Diretório da Pastoral Familiar, Documentos da CNBB 79, Paulinas, São Paulo, 2005.

\section{Autores}

AAVV, La riforma dei processi matrimoniali di Papa Francesco: una guida per tutti. Ancora, Milano, 2016. 
C. IZZI, Valutazione del fondamento antropologia dela perizia. Studio sulla recente giurisprudenza rotale in tema d'incapacità consensuale, Quaderni di Apollinaris, Lateran University Press, Roma, 2004.

, I ministri di giustizia in genere, in AAVV, Il giudizio di nulità matrimoniale dopo l'istruzione "Dignitas Connubii". Parte Seconda: La parte statica del processo. Libreria Editrice Vaticana, Città del Vaticano, 2007.

J. A. GONÇALVES DE ALMEIDA (organizador), Vade-mécum do Motu Proprio Mitis Iudex Dominus Iesus, CNBB, Brasília, 2017.

J. F. GUIMARÃES, As Câmaras Eclesiásticas: agilização da justiça eclesiástica, in Revista Direito \& Pastoral, Ano VII, julhosetembro de 1993, nº 27, pp.31-38.

L. GHISONI, I ministri di giustizia in specie: uditori e assessori, in AA.VV, Il giudizio di nullità matrimoniale dopo l'istruzione Dignitas Connubii, Libreria Editrice Vaticana, Città del Vaticano, 2007, pp. 157-175.

M. J. ARROBA CONDE, Diritto processuale canonico, $6^{\mathrm{a}}$ ed., Ediurcla, Roma, 2012.

, Principi di deontologia forense canônica, in AAVV, Il diritto di difesa nel processo matrimoniale canonico, Libreria Editrice Vaticana, Città del Vaticano, 2006, pp. 138-140.

M. J. ARROBA CONDE - C. IZZI, Pastorale giudiziaria e prassi processuale nelle cause di nullità del matrimonio, San Paolo, Milano, 2017.

V. J. RIBEIRO, A reforma do processo de nulidade matrimonial: um exame do Motu proprio Mitis Iudex Dominus Iesus, CNBB, Brasília, 2016.

V. J. RIBEIRO - D. GERALDO, A reforma no processo de nulidade matrimonial e sua gênese no Sínodo dos Bispos, in Revista Eclesiástica Brasileira (REB), v. 302, 2016, pp. 356-374. 